\title{
Renal Involvement in Sarcoidosis
} Key words: hypercalcemia, granulomatous interstitial nephri-
tis, glomerulonephritis

Sarcoidosis is a systemic disease characterized by the histologic granulomatous lesion. Sarcoidosis often affects the kidney as well as lung, skin and eye. Understanding of possible mechanisms of granuloma formation has been recently progressed by immunological studies (1). At the active site of the disease, lymphocytes and macrophages are activated. Activated macrophages in cooperation with $\mathrm{T}$ lymphocytes induced proliferation of activated helper $\mathrm{T}$ cells. These activated cells release several mediators including interleukin- 2 which contribute to the further recruitment of circulating monocytes and $T$ lymphocytes. These cells enhance the inflammatory process leading to granuloma formation.

Renal manifestations in sarcoidosis commonly consist of disordered $\mathrm{Ca}$ metabolism, interstitial noncaseating granulomas and glomerular lesions. Hypercalcemia is observed in approximately 2.5 to $17 \%$ of patients with sarcoidosis (2). Hypercalcemia, followed by hypercalciuria, is involved in an impaired urine concentration, decreased glomerular filtration and nephrocalcinosis. The mechanism of hypercalcemia in this condition is now established (2). In active stages of the disease, a large amount of calcitriol is released from activated macrophages in granulomas. An increased circulating level of calcitriol is responsible for increased intestinal calcium absorption and increased bone resorption. These two factors lead to increases in the filtered load of calcium which, in association with suppressed parathyroid hormone activity, results in elevated urinary calcium excretion. Corticosteroids are very effective in decreasing high serum calcium levels and improving renal function within a few days (3). Corticosteroids suppress calcitriol synthesis by inhibiting macrophage $1 \alpha$-hydroxylase activity, thereby decreasing intestinal calcium absorption and bone resorption.

Granulomatous interstitial nephritis usually occurs in 15$40 \%$ of patients with sarcoidosis (4). Clinically, renal dysfunction develops often slowly over weeks or months. But some patients undergo acute renal failure. Proteinuria or hematuria is not present or is mild. Tubular abnormalities such as glycosuria, tubular acidosis and decreased urine concentrating ability are found in many cases (5). Hypercalcemia may also play a role on these renal functional abnormalities. Histologically, the interstitial granulomas are the predominant manifestation which is composed of giant cells, B cells, plasma cells and T cells, with a predominance of helper $\mathrm{T}$ cells. The extent of the lesion is variable, but in some cases the granulomatous lesion replaces the majority of the cortical volume, severely distorting the tubular architecture (5). Usually, immunofluorescence and electron microscopic studies demonstrate no immune deposits in either glomeruli or tubules. Angiotension converting enzyme is localized in the granulomas, specifically in this disease (6). Granulomatous interstitial nephritis is usually treated by corticosteroids. After starting steroid therapy renal function can improve rapidly. Corticosteroid treatment of less than 6 months duration is frequently followed by relapse. Thus, the treatment should be maintained for at least one year (7). Repeated biopsies show regression of granulomas and lymphocyte infiltrate (8). However, in spite of steroid therapy, improvement of renal function is not always obtained due to the development of interstitial fibrosis (9).

See also $\mathrm{p} 241$.

Glomerulonephritis is rarely associated with sarcoidosis. In some case reports, membranous nephropathy (10), membranoproliferative glomerulonephritis (11), rapidly progressive glomerulonephritis (12), IgA nephropathy (13), minimal change nephrotic syndrome (14) and focal glomerulosclerosis (15) are documented. Postinfectious glomerulonephritis is also reported (16). Particularly, membranous nephropathy is frequently associated with sarcoidosis. Vanhille et al (13) reviewed 13 cases with membranous nephropathy which in most cases occurred late in the course of an overt sarcoidosis. It is possible that both humoral and cellular immune abnormalities may induce the development of glomerulonephritis. In some cases with sarcoidosis, the coexistence of glomerulonephritis and granulomatous interstitial nephritis is observed $(17,18)$. Corticosteroid treatment is also effective in reducing proteinuria and preserving renal function in most cases with glomerulonephritis.

Yutaka KoBAYASHI, MD The Department of Medicine, Kitasato University School of Medicine, 1-15-1, Kitasato, Sagamihara, Kanagawa 228-8555

\section{References}

1) Kenouch S, Mery JP. The patient with Sarcoidosis. in: Oxford Textbook of Clinical Nephrology. 2nd ed. AM Davison AM et al, Ed. Oxford University Press, Oxford, 1998: 837-843.

2) Coburn JW, Barbour GL. Vitamin D Intoxication and Sarcoidosis. in: Hyercalciuric States. Pathogenesis, Consequences and Treatment. Coe FL, Ed. Grune and Stratton, Orlando, FL, 1984: 379-433.

3) Nordal KP, Dahl E, Halse J, Aksnes L, Aarskog D. Rapid effect of pred- 
nisolone on serum 1, 25-dihydroxycholecalciferol levels in hypercalcemic sarcoidosis. Acta Med Scand 218: 519-523, 1985.

4) Muther RS, McCarron DA, Bennett WM. Renal manifestations of sarcoidosis. Arch Intern Med 141: 643-645, 1981.

5) Muther RS, McCarron DA, Bennett WM. Granulomatous sarcoid nephritis: A cause of multiple renal tubular abnormalities. Clin Nephrol 14: 190-197, 1980

6) Ito $Y$, Suzuki T, Mizuno M, et al. A case of renal sarcoidosis showing central necrosis and abnormal expression of angiotensin converting enzyme in the granuloma. Clin Nephrol 42: 331-336, 1994.

7) McCurley T, Salter J, Glick A. Renal insufficiency in sarcoidosis. Arch Pathol Lab Med 114: 488-492, 1990.

8) Farge D, Liote F, Turner M, Barre P, Jothy S. Granulomatous nephritis and chronic renal failure in sarcoidosis. Long-term follow-up studies in two patients. Am J Nephrol 6: 21-27, 1986.

9) Ikeda A, Nagai S, Kitaichi M, et al. Sarcoidosis with granulomatous interstitial nephritis: Report of three cases. Intern Med 40: 241-245, 2001.

10) Taylor RG, Fisher C, Hoffbrand BI. Sarcoidosis and membranous glomerulonephritis: A significant association. Br Med J ( Clin Res Ed) 284 (6325): 1297-1298, 1982.

11) Molle D, Baumelou A, Beaufils H, Vannier R, Legrain M. Membranoproliferative glomerulonephritis associated with pulmonary sarcoidosis. Am J Nephrol 6: 386-387, 1986

12) Auinger $M$, Irsigler $K$, Breiteneder $S$, Ulrich W. Normocalcemic hepatorenal sarcoidosis with crescentic glomerulonephritis. Nephrol Dial Transplant 12: 1474-1477, 1997.

13) Vanhille $P$, Beaudoin $D$, Mougenot $B$, et al. Rapidly progressing glomerulonephritis with mesangial IgA deposits in sarcoidosis. Nephrologie 7: 207-209, 1986.

14) Mundlein E, Greten T, Ritz E. Graves' disease and sarcoidosis in a patient with minimal-change glomerulonephritis. Nephrol Dial Transplant 11: 860-862, 1996.

15) Peces R, de la Torre M, Sanchez-Fructuoso A, Escalada P: Focal segmental glomerulosclerosis associated with pulmonary sarcoidosis. Nephron 65: 656-657, 1993 (letter).

16) Michaels S, Sabnis SG, Oliver JD, Guccion JG. Renal sarcoidosis with superimposed postinfectious glomerulonephritis presenting as acute renal failure. Am J Kidney Dis 36 (1): E4, 2000.

17) Khan IH, Simpson JG, Catto GRD, MacLeod AM. Membranous nephropathy and granulomatous interstitial nephritis in sarcoidosis. Nephron 66: 459-461, 1994.

18) Toda T, Kimoto S, Nishio Y, Ehara T, Sasaki S. Sarcoidosis with membranous nephropathy and granulomatous interstitial nephritis. Intern Med 38: 882-886, 1999. 